\title{
What to Do When A Patient Infected With COVID-19 Needs An Operation: A Pre-surgery, Peri-surgery and Post-surgery Guide
}

\section{COVID-19 ile Enfekte Bir Hastasının Operasyona İhtiyacı Olduğunda Ne Yapmalıyız: Cerrahi Öncesi, Cerrahi Sırası ve Cerrahi Sonrası Rehberi}

\author{
(1) Erdinç Kamer1, (1) Tahsin Çolak² \\ ${ }^{1}$ İzmir Katip Çelebi University Atatürk Training and Research Hospital, Clinic of General Surgery, İzmir, Turkey \\ 2Mersin University Faculty of Medicine, Department of General Surgery, Mersin, Turkey
}

\begin{abstract}
HIIIIII| ABSTRACT
The virus, called COVID-19, which has emerged in China in December 2019, has been known to spread through droplets and close contact, and has evolved into a pandemic today. It is also known that in all patients who have come into contact with COVID-19, the infection is not severe and may even occur without symptoms. There is no consensus yet on how to take measures to protect the patient and the surgeon in case of diseases requiring urgent or elective surgery, and how preoperative preparation, perioperative phase, and postoperative care should be performed. The aim of this study was to prepare a guide on how the surgeon should behave in patients whose operation is mandatory in light of the available data.
\end{abstract}

Keywords: COVID-19, carona SARS-CoV-2, surgery guidelines

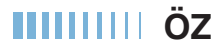

Aralık 2019'da Çin'de orta çıkan damlacık ve yakın temas yoluyla yayıldığı bilinen COViD-19 olarak adlandırılan virüs hastalığı günümüzde pandemiye dönüşmüştür. COVID-19 ile temas etmiş hastaların tümünde enfeksiyonun şiddetli olmadığı ve hatta semptomsuz seyredebileceği de bilinmektedir. Bu kişilerde acil veya elektif cerrahi yapılmasını gerektiren hastalıklar olması durumunda hastayı ve cerrahı koruyacak önlemlerin nasıl alınması gerektiği, ameliyat öncesi hazırlık, perioperatif faz, ve postoperatif bakımın nasıl yapılması gerektiği konusunda henüz fikir birliği oluşmamıştır. Bu çalışmada eldeki veriler ışığında operasyonu zorunlu olan hastalarda cerrahın nasıl davranması gerektiği konusunda bir kılavuz hazırlanması amaçlandı.

Anahtar Kelimeler: COVID-19, carona SARS-CoV-2, ameliyat kuralları

\section{Introduction}

It is known that an outbreak in the form of pneumonia of unknown origin has occurred in Wuhan in China's Hubei Province in December 2019, killing 213 of the 9720 infected people in China and spreading in 19 other countries, infecting 106 people by January 31, 2020. ${ }^{1}$ The causative virus has been tentatively named "Severe Acute Respiratory Syndrome Coronavirus 2" (SARS-CoV-2) and finally named
"Coronavirus Disease 2019 (COVID-19) by the World Health Organization. The disease is most commonly seen between the ages of 30-79 years and the median age is in the range of 49-59 years. It has been found very rarely under the age of 15. In about half of people infected with COVID-19, non-serious or overlooked symptoms occur, while in the other half the main symptoms are fever, fatigue and dry cough, myalgia and dyspnea. ${ }^{2,3}$ About half of the patients

Address for Correspondence/Yazışma Adresi: Erdinç Kamer MD,

İzmir Katip Çelebi University Atatürk Training and Research Hospital Clinic of General Surgery, İzmir, Turkey

Phone: +90 5323525261 E-mail: erdinc.kamer@gmail.com ORCID ID: orcid.org/0000-0002-5084-5867

Received/Geliş Tarihi: 20.03.2020 Accepted/Kabul Tarihi: 20.03.2020

${ }^{\circ}$ Copyright 2020 by Turkish Society of Colon and Rectal Surgery

Turkish Journal of Colorectal Disease published by Galenos Publishing House. 
have co-existing diseases such as hypertension, diabetes and cardiovascular disease. ${ }^{3}$ The most common laboratory findings are leukopenia and lymphopenia. Elevation in lactate dehydrogenase and creatinine kinase levels can also be seen. Half of the patients may have abnormal liver function test findings such as elevation in alanine aminotransferase or aspartame aminotransferase levels. In most patients, normal serum procalcitonin levels are observed, but C-reactive protein levels are higher than the normal range. D-Dimer is high in a third of patients. ${ }^{4,5}$

The risk of respiratory failure requiring critical care support in patients infected with COVID-19 is significant and prioritized, so critical care and anesthesiology teams should be prepared for the treatment and ongoing care of patients infected with COVID-19. ${ }^{6}$

Although there are studies focusing on the epidemiology, pathophysiology and management, best practices and their effect on public health outcomes in COVID-19-infected patients; the algorithm for surgical treatment of COVID-19infected patients is still seen as an insignificant, secondary health problem. In addition, while anesthesiologists provide guidance on the equipment and preservatives needed to protect themselves during intubation, we surgeons are still a little behind on this issue. ${ }^{7}$ However, there is a need for guidance on how to follow these patients in situations that require elective, emergency or mandatory surgery.

The SARS experiences of many countries, such as Canada, create optimal care conditions to keep health workers safe in intervening patients infected with COVID-19, while countries without SARS experience such as Turkey, it is indisputable that health workers will be at great risk in intervening patients infected with COVID-19. On the other hand, the fact that patients with no symptoms or mild symptoms are more easily able to contact health workers increases both the spread of the disease and the risk to health workers. It has been proven that New Corona virus pnönoni (NCP) can be transmitted from person to person and can cause hospital infection that seriously threatens surgical staff and inpatient staff. ${ }^{8}$ Ti LK et al. ${ }^{7}$ suggested an operating room (OR) protocol prepared for confirmed or suspected COVID-19 infected patients who came to their hospital for surgery. As they suggested an OR protocol for the preparation period, intraoperative and postoperative phases for the nurse in charge, surgical staff, surgical nurse, anesthesiologist, anesthesia technicians and OR technicians; "the surgeon" was not included in this protocol.

Although we have experience in surgical procedures in patients with hepatitis, cyst hydatid and HIV infection, we do not currently have any experience with COVID-19 infected patients.Protection of health workers, other patients and wards, perioperative treatment, measures for operating rooms and surgical instruments, and operational, perioperative and postoperative management should be defined and known in detail in case of emergency operation in patients with suspected or confirmed COVID-19 infection. This will give health workers, especially surgeons, both protection from the disease and legal advantage.

In this study, it was aimed to establish a guide for establishing optimum protection conditions that could be done before, during and after surgical intervention, as specialists of surgical branches and anesthesiologists were at great risk in the treatment of patients infected with COVID-19.

In patients with suspected or approved COVID-19 infection, it is obvious that a special procedure should be performed beginning from the entry of patients to the hospital until their discharge from hospital. It is possible to evaluate the process from the point of view of the surgeon in 3 sub-sections: Evaluation phase, perioperative phase, and postoperative phase.

\section{Evaluation Phase}

A patient with suspected or confirmed COVID-19 infection may come to the surgical service from an outpatient clinic or emergency department following normal procedures. In both cases, the first evaluation of such patients should be done in a protected area that is predetermined according to the protocols of your hospital. First of all, elective surgery and endoscopic procedures should be postponed. This minimizes the risk for both the patient and the medical team, while minimizing the exposure of beds, ventilators, personal protective equipment (PPE), health care providers and other patients. In cases requiring emergency surgery, it is important to evaluate the suspected and confirmed patients in 2 separate groups. Although the protective measures to be taken during the evaluation are similar, treatment options may vary.

The following suggested path can be followed in the initial evaluation of the patient.

\section{Preliminary evaluation:}

- The patient's file should be examined in a safe area before contact with the patient. In this examination, previously recorded medical history, tests such as CT imaging that have been done, should be evaluated.

- The patient is reviewed with other intervening doctors, information is obtained from the family in terms of other aspects not reflected in the patient's medical history and all these data are recorded. 


\section{Preparation for Examination}

- After that, the first thing to do is to go to the area near the room where PPE will be worn, along with doctors, nurses and assistants, to examine the patient. All items must be left in a safe area, hair must be collected, the top of the uniform must be tucked into the trousers. The shoes should also be made of sterilizable material that covers the feet and ankles exactly, such as boots, without holes and if possible, and the pants' legs should be inserted into the boot. After preparation, a cap covering the head and neck, protective mask, inner gloves, apron, outer gloves are worn, followed by glasses or face protective transparent barrier is worn. After the preparation is completed, the room is entered from its clean entrance and the patient is reached by following the shortest path without touching the items in the room.

\section{Examination}

- Anamnesis: The patient may not know who you are because of the PPE you wear. It is therefore recommended that you introduce yourself. Anamnesis should not be kept long due to the discomfort of the environment, should be clear and concise.

- Physical examination: Routine standards should be done. Due to the noise of the environment and isolations, most of the time there may not be auscultation. Standard equipment (sterile gloves, lubricants, gauze, etc.) can be used when there is a surgical wound or mucosa that needs to be evaluated or rectal examination that needs to be performed.

\section{Leaving the Room}

- Since the area where the patient is examined is considered to be a contaminated area, after the examination, we should go to the exit section where the auxiliary team is waiting for us. We have to wash hands with antiseptic without removing anything and then remove PPE with the help of a support team. We often wash our hands with virucidal products. Especially caution should be exercised because contamination may be most common in this area.

\section{Consultation}

- When the cleaning process is complete, the treatment protocol is determined by consulting with the other doctors involved in the case and the result is notified to the family by telephone. The goal here is to have as little contact as possible.

\section{Consent}

- Everything that is done must be written and recorded on the computer on a regular basis. However, signed consent may not be obtained for security reasons.

On the other hand, surgery should not be delayed until diagnostic tests for COVID-19 are concluded if undiagnosed but suspicious patients are to undergo elective surgery. ${ }^{6,7}$ Patients with COVID-19 infection who need surgery will follow the same protocols as any other patient. In such cases, the rational use of available resources should be prioritized and both stigma of patients and the occurrence of unnecessary alarm situations should be avoided

\section{Perioperative Phase}

\section{- Before Surgery}

In patients with confirmed or suspected COVID-19 infection, all operating room personnel are required to wear PPE under their surgical dress to prevent contamination. PPE is essential for all interventions requiring close contact, such as surgical intervention, intubation, regional anesthesia, cannulation or catheterization. It is essential that all personnel and surgeons are trained to prevent contamination during the wearing and removal of these PPEs (Table 1).

There are different types of PPE, but the basic equipment needed to perform a surgical intervention can be summarized as follows:

Table 1: Personal protective equipment usage when intervening COVID-19 infected patients ${ }^{8}$

\begin{tabular}{|c|c|c|}
\hline $3^{\text {rd }}$ level protection & $\begin{array}{ll}\text { - } & \text { Disposable surgical cap } \\
\text { - } & \text { Protective medical mask (N95) } \\
\text { - } & \text { Dork clothes } \\
\text { - } & \text { Disposable protective suit } \\
\text { - } & \text { Protective glasses } \\
\text { - } & \text { All face respiratory protective equipment or } \\
& \text { motorized air purifying respirator }\end{array}$ & $\begin{array}{l}\text { - Should be used during operations such as tracheal } \\
\text { intubation, tracheotomy, bronchofibroscopy, } \\
\text { gastroenterological endoscopy in patients with } \\
\text { suspected or confirmed COVID-19 infection } \\
\text { because these patients may spray or splash } \\
\text { respiratory secretion, blood or body fluid } \\
\text { - Should be used when medical personnel perform } \\
\text { surgery or autopsy on the suspected or confirmed } \\
\text { patient } \\
\text { - Should be used by personnel when performing } \\
\text { COVID-19 NAT }\end{array}$ \\
\hline
\end{tabular}




\section{Waterproof Apron}

2. Mask: Traditional surgical mask does not provide protection if aerosols are present. N95 or FFP2/FFP3 type masks are required.

3. Glasses or face protective transparent barrier. But if the procedure produces aerosols, full-size barrier eye coverage is required. If not, just a partial barrier may be enough to prevent splashing or direct contamination.

\section{Latex gloves}

5. It is recommended that all long-haired staff hold their hair under the bonnet and, if they have a beard, they should cut to make masks comfortable to sit.

6. Shoes must be without holes and cover the whole foot. Sterile rubber boots should be worn if possible

7. After these preparations, standard sterile surgical aprons should be worn. Before surgical gloves are worn, the lower gloves should be washed with virucidal agents or alcohol.

Since the mortality risks of COVID-19 infected patients who are diagnosed in preoperative period and need to be taken to emergency surgery are very high, the patients and their families should be informed about this. During the outbreak, the same OR and the same anesthesia device should be used in the operations of COVID-19 infected patients. ${ }^{6}$

The surgical team to make contact with critically ill patients with confirmed or suspected COVID-19 infection should use a properly tested N95 respiratory mask, eye protection, full face cover, liquid-resistant apron, long boots and rubber gloves (Picture 1). ${ }^{6}$ Longer-sleeved gloves are preferred to prevent glove slip. Alternatively, vertical tape strips may be used to help secure the gloves to the dress. ${ }^{6}$ The use of new type surgical gloves or synthetic gloves with disinfectant agent between the two layers may provide disinfection (G-VIR) in case of puncture. It is also recommended to use such gloves. ${ }^{9}$ Jumpsuits with an integrated headgear can simplify the substrate worn, but product selection must be assessed for ease of removal to prevent contamination during removal.

\section{- Surgery}

On the other hand, it is still debatable whether the surgical procedure to be applied to these patients should be performed with laparoscopic or conventional methods. As is known, the experiences so far are early results from case reports or case series. Therefore, according to the low level evidences, the risk of viral contamination that may occur with aeresol effect of the gas used in laparoscopic surgery or surgical smoke should be taken into consideration while surgical team's contact with the patient's fluids and tissues increases with conventional method. On the other hand, laparoscopic operations create a physiological functional barrier between the surgeon and the disease because the abdomen is not opened, reducing exposure to the disease and cross infections. On the other hand, it may be necessary to avoid prolonged laparoscopic operations. Constant pressure insufflators can be used to reduce the aerosol effect of insufflation, and central aspirator systems must be used to drain the smoke. Although these characteristics of coronavirus are unknown, it has been determined that other viruses, such as Hepatitis B virus, can be found in surgical smoke formed during laparoscopy. For laparoscopic procedures, the use of $\mathrm{CO}_{2}$ filters for aerosolized particles should be strongly considered. Yu GY et al. ${ }^{10}$ have shown that SARS-Cov-2 is transmitted by droplet and contact paths, but fecal-oral and aerosol paths can not be ignored.
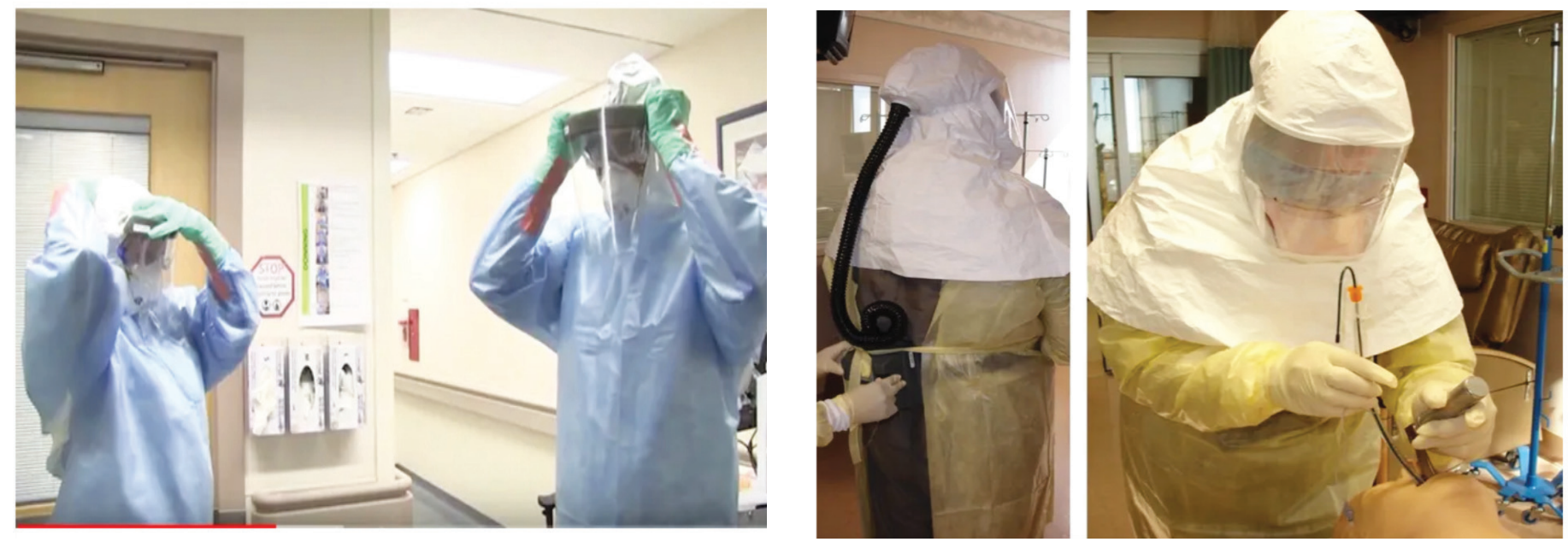

Figure 1: Personal protective equipment. "WaxRS, ChristianMD. Practical recommendations for critical care and anesthesiology teams caring for novel coronavirus (2019-nCoV) patients. Can J Anaesth. 2020 Feb 12. doi: 10.1007/s12630-020-01591-x". ${ }^{6}$ 
Also, it has been shown that laparoscopic surgery operations can be performed in patients with colon cancer infected with COVID-19, but the necessity of managing laparoscopic gases is emphasized and NOSES and TaTME operations are recommended to be performed carefully during the epidemic period. ${ }^{10}$ Luo Y et al. published a paper called the "Renji Experience". That article stated that although colorectal surgery was not a priority in the fight against COVID-19, there might be a need to treat colon cancer and the highest level of protection for patients and their families, the health of medical personnel and other patients, and the safety of wards and hospitals could be provided in such a case. ${ }^{11}$ In that study, it was stated that diagnosis and treatment of COVID-19 infected patients with colorectal cancer should not just be done by routine departments and should be conducted by a multidisciplinary team including departments of respiratory diseases and infectious diseases. It was stated that colonoscopy was inadvisable except in emergency and life threatening situations (bleeding, obstruction, foreign bodies, etc.), because it might cause cross-infection in patients and other health care workers and that even in these cases colonoscopy should not be performed and surgery should be the first preferred. It was also stated that COVID-19 infected patients with colorectal cancer should be placed in the isolation room with separate medical devices and that negative pressure rooms (below 5 PA) should be prepared and that all disposable medical products, body fluids and feces should be disposed of after surgery according to standard medical waste protocol and that after surgery, health workers were told to be taken for observation and isolated for 14 days. ${ }^{10,11}$ On the other hand, Chen YH et al. ${ }^{12}$ stated that surgical operation should be reduced to a minimal level to prevent cross-infection in this special period and that surgical interventions for benign tumors should be postponed and that multidisciplinary treatment and non-surgical anti-tumor treatment should be chosen with a higher priority for malignant tumors, and that neoadjuvant therapy was highly recommended to the advanced stage cancers of the gastrointestinal tract meeting the criteria of NCCN guideline, and that in patients with a malignant tumor causing obstruction in gastric or esophagogastric junction could be managed with gastric tube decompression or stent placement to alleviate symptoms, and that transnasal enteral feeding tube intubation/percutaneous endoscopic gastrostomy could be used to provide enteral nutrition, and that stent placement for colorectal malignancy leading to simple bowel obstruction could not only help you avoid emergency surgery, but also could provide a high success rate for future surgery, and that transcatheter arterial embolization could be an alternative choice to treat bleeding gastrointestinal tumors, and that emergency surgery could be a necessity in case of uncontrolled bleeding, blockage, or failure to other alternative treatments. ${ }^{12}$ All invasive interventions should be performed in a designated isolation area. Protective enterostomy is a preferred method in lower digestive system surgery. ${ }^{12}$

In addition, it is still unknown how the intraoperative and postoperative wastes of these patients (including aspirator content, organs, feces, urine, used surgical materials) will be disposed of. It is also not known how to send the tissue samples that come out during surgery to pathology and how they will be subjected to a procedure in pathology, how to protect the pathologists and how to store the preparations. However, standard practices are recommended for these wastes.

\section{After Surgery}

Disinfection procedures for the isolation area such as the OR during the post-operative period are detailed in the "Covid-19 Prevention and Treatment Manual" prepared by CAI Hongliu et al. ${ }^{8}$ Accordingly;

For the disinfection of floor and wall; 1) Visible contamination must be completely removed before disinfection; blood and body fluids cleaning procedures should be followed; 2) The floor and walls should be disinfected with a disinfectant containing $1000 \mathrm{mg} / \mathrm{L}$ chlorine via floor mopping, spraying or cleaning; 3) It should be ensured that disinfection was performed for at least 30 minutes; 4) The disinfection process should be done three times a day and the procedure must be repeated in case of contamination. ${ }^{8}$

For the disinfection of object surfaces; 1) Visible contamination must be completely removed before disinfection; blood and body fluids cleaning procedures should be followed; 2) The surfaces of objects should be wiped with cloths containing disinfectants of $1000 \mathrm{mg} / \mathrm{L}$ chlorine and it should be rinsed with clean water after 30 minutes. The disinfection procedure should be performed three times a day (should be repeated when contamination is suspected); 3) First clean areas, then more contaminated areas should be wiped. First the surfaces of objects which are not frequently touched should be wiped and then the surfaces of frequently touched objects should be wiped (when the surface of an object is cleaned, replace the used wiper with a new one). ${ }^{8}$

For Air disinfection; 1) Plasma air sterilizers can be used for air disinfection in environments where humans are present and can be operated continuously; 2) If plasma air sterilizers 
are not available, an ultraviolet lamp should be used for 1 hour at a time. This should be done three times a day. ${ }^{8}$

For removal of faeces and sewage water; 1) Fecal matter and sewage system should be disinfected by purifying with disinfectant containing chlorine before it is sent to the drainage system (active chlorine should be more than 40 $\mathrm{mg} / \mathrm{L}$ for the first application.). Ensure that the disinfection time is at least 1.5 hours; 2) The total residual chlorine concentration in the disinfected sewage system should reach $10 \mathrm{mg} / \mathrm{L} .{ }^{8}$

Protection Against Spill of Blood and Fluids of The Patients with COVID-19 infection ${ }^{8}$;

In case of a small amount (10 mL) of blood or body fluid is spilled; 1) Option 1: Spills must be carefully covered with disinfectant wipes containing chlorine (containing 5000 $\mathrm{mg} / \mathrm{L}$ effective chlorine) and cleared, then the surfaces of the objects should be cleared with disinfectant wipes containing chlorine (containing $500 \mathrm{mg} / \mathrm{L}$ effective chlorine) for the second time with; 2) Option 2: Spills should be carefully eliminated with disposable absorbent materials such as gauze, wipe, etc. soaked in disinfectant solution containing $5000 \mathrm{mg} /$ L chlorine. $^{8}$

In case of a large amount ( $>10 \mathrm{~mL}$ ) of blood or body fluid is spilled; 1) first, place signs that indicate the presence of a spill; 2) apply clearing procedures described below in option 1 or 2: Option 1: Put a clean and absorbent towel on spills for 30 minutes (towels must contain peroxyacetic acid, which can absorb liquid up to $1 \mathrm{~L}$ ) and clean the contaminated area after removing contaminated substances. Option 2: Completely cover the spill with disinfectant powder or bleach powder containing water-absorbing ingredients, or completely cover it with disposable water-absorbing materials. Then pour disinfectant containing $10,000 \mathrm{mg} / \mathrm{L}$ chlorine into the water-absorbing material (or cover it with a dry towel which will undergo high-level disinfection). Wait for at least 30 minutes before carefully removing the spill. 3) fecal matter, secretions, vomiting etc. taken from patients should be collected in special containers and should be disinfected for 2 hours with 20,000 mg/L chlorine-containing disinfectant (1:2 pouring/disinfectant); 4) after removing the spill, disinfect the surfaces of the contaminated environment or objects; 5) containers containing infected materials should be cleaned with a disinfectant containing $5,000 \mathrm{mg} / \mathrm{l}$ active chlorine for 30 minutes; 6) collected infected substances must be disposed of as medical waste; 7) used products should be placed in double layer medical waste bags and disposed of. ${ }^{8}$
For decontamination of reusable medical devices; 1) Keep the device for at least 30 minutes in disinfectant containing $1000 \mathrm{mg} / \mathrm{L}$ chlorine if there is no visible contamination; 2) if there is visible contamination, keep the device for at least 30 minutes in disinfectant containing $5000 \mathrm{mg} / \mathrm{L}$ chlorine; 3) after drying, package the devices, close them completely and send them to the disinfection center. ${ }^{8}$

There is no guide on how to transport pathology preparations, how to process them, how to protect pathologists and how to store preparations. It has been suggested that a runner must be present outside the OR, and that such personnel must provide medicines or equipment when needed, or that they are required for arterial blood gas or frozen sectio operations. ${ }^{6,7}$ Staff leaving the OR throw away their used gowns and gloves in the entrance room and perform hand hygiene before leaving the entrance room. ${ }^{6,8}$ At the end of the surgery, one of the most important phases is for the team to remove their clothes before leaving the operating room to prevent contamination. At this stage, the team should move away from the patient with slow movements, avoid contact with each other. They should help each other during dressing and the basic principles of contamination prevention should be followed. Frequently the hands should be washed with virucidal agents or alcohol. The clothes should be in the dirty room or in the same OR at a remote point and, if possible, right next to the OR door. For this reason, ORs with large or sufficient space should be preferred to minimize contact. ${ }^{8}$

\section{Postoperative Phase}

Patients who do not require postoperative ICU care are kept in the operating room until complete recovery. ${ }^{6}$ After the OR personnel send the patient back to the service, a minimum of one hour is required between cases to clean all contaminated surfaces, screens, keyboards, cables, monitors and anesthesiology machine. Products not used in surgery should be considered infected. All staff are also required to shower before continuing their duties. Decontamination of OR should be provided by vaporizer using hydrogen peroxide. ${ }^{6,7}$

Airflow in hospital wards can significantly affect the risk of nosocomial transmission of certain coronavirus strains, such as SARS. ${ }^{14}$ During the previous SARS outbreak, hospital administrations modified existing hospital systems to create negative airflow isolation rooms. In some cases, all intensive care units were converted into negative pressure/ airflow services instead of individual patient rooms. These strategies used during the SARS experience can be replicated 
if necessary when managing 2019-nCoV outbreak scenarios, with local operational limitations and capabilities in mind.

After the OR, patients should be monitored and treated in isolated intensive care units or in isolated rooms in accordance with hospital protocols. The basic rules mentioned above should be followed when taking care of the patients. On the other hand, it is debatable whether treatment for COVID-19 should be given during postoperative follow-up, besides giving disease-specific treatments. Since postoperative respiratory problems are more frequent than usual in these patients, a multidisciplinary approach with anesthesiologist and chest diseases specialist is required. If COVID-19 infection has not been proven in patients, there is no need to provide specific treatment for Coronavirus in these patients. Treatment should be administered as it is done to other patients. ${ }^{6}$ However, if patients have a confirmed diagnosis of COVID-19 infection, treatment for the coronavirus may be given. There is no consensus on the treatment to be given and the treatment is updated daily. Since the side effects and efficacy of the treatments are not certain, at least oral consent should be obtained from the patient before starting the treatment. Hydroxychloroquine, lopinavir/ritonavir are treatments currently used..$^{15}$ Only hydroxychloroquine should be used in elderly patients using multidrugs. However, this medication should be avoided in case of liver disease. ${ }^{15}$ In addition to these treatments in patients with severe infection, Interferon/Tocilizumab may be added to treatment. ${ }^{16}$ Remdesavir may also have a role in the treatment. ${ }^{17}$ Oxygen therapy and $\mathrm{N}$-acetylcysteine should also be given. Drugs that alter function and expression of angiotensin converting enzyme 2 (ACE-2) are being evaluated. However, corticosteroid therapy should be avoided. Although there is no conclusive evidence, NSAIDs such as iboprufen are not recommended because they can worsen the disease. In the case of intrabadominal infection, it is not recommended to change the protocol applied in the treatment of intrabdominal infection.

In countries such as Turkey which are new to COVID-19; health care services, health centers, intensive care units and ORs should be reviewed. Each section should create its own protocol and guide and while doing this; protocols, algorithms, and guides that that have been created by countries such as Canada which has the SARS experience should be taken into account. We believe that we will be able to overcome this outbreak by ensuring the health of the patients infected with COVID-19 and the safety of the medical staff who encounter these patients.
Peer-review: Internally peer reviewed.

\section{Authorship Contributions}

Concept: E.K., T.Ç., Design: E.K., T.Ç., Data Collection or Processing: E.K., T.Ç., Analysis or Interpretation: E.K., T.Ç., Literature Search: E.K., T.Ç., Writing: E.K., T.Ç.

Conflict of Interest: No conflict of interest was declared by the authors.

Financial Disclosure: The authors declared that this study received no financial support.

\section{References}

1. He F, Deng Y, Li W. Corona virus Disease 2019 (COVID-19): What we know? J Med Virol 2020.

2. Lu R, Zhao X, Li J, Niu P, Yang B, Wu H, et al. Genomic characterisation and epidemiology of 2019 novel coronavirus: implications for virus origins and receptor binding. Lancet 2020;395:565-574.

3. Wu Z, McGoogan JM. Characteristics of and Important Lessons From the Corona virus Disease 2019 (COVID-19) Outbreak in China: Summary of a Report of 72314 Cases From the Chinese Center for Disease Control and Prevention. JAMA 2020

4. Li Q, Guan X, Wu P, Wang X, Zhou L, Tong Y, et al. Early Transmission Dynamics in Wuhan, China, of Novel Coronavirus-Infected Pneumonia. N Engl J Med 2020.

5. Wang D, Hu B, Hu C, Zhu F, Liu X, Zhang J, et al. Clinical Characteristics of 138 Hospitalized Patients With 2019 Novel Coronavirus-Infected Pneumonia in Wuhan, China. JAMA. 2020;323:1061-1069.

6. WaxRS, ChristianMD.Practical recommendations for critical care and anesthesiology teams caring for novel coronavirus (2019-nCoV) patients. Can J Anaesth 2020

7. Ti LK, Ang LS, Foong TW, Ng BSW. What we do when a COVID-19 patient needs an operation: operating room preparation and guidance. Can J Anaesth 2020

8. CAI Hongliu, CHEN Yu, CHEN Zuobing, FANG Qiang, HAN Wei li et al LIANG tT(Ed). "Handbook of COVID-19 Prevention and Treatment", The First Affiliated Hospital, Zhejiang University School of Medicine, 2020

9. Caillot JL, Voiglio EJ. First clinical study of a new virus-inhibiting surgical glove. Swiss Med Wkly 2008;138:18-22.

10. Yu GY, Lou Z, Zhang W. Several suggestion of operation for colorectal cancer under the outbreak of Corona Virus Disease 19 in China. Zhonghua Wei Chang Wai Ke Za Zhi 2020;23:9-11.

11. Luo Y, Zhong M. Standardized diagnosis and treatment of colorectal cancer during the outbreak of novel coronavirus pneumonia in Renji Hospital. Zhonghua Wei Chang Wai Ke Za Zhi 2020;23:E003.

12. Chen N, Zhou M, Dong X, Qu J, Gong F, Han Y, et al. Epidemiological and clinical characteristics of 99 cases of 2019 novel corona virus pneumonia in Wuhan, China: a descriptive study. Lancet 2020;395:507-513.

13. Chen YH, Peng JS. Treatment strategy for gastrointestinal tumor under the outbreak of novel coronavirus pneumonia in China. Zhonghua Wei Chang Wai Ke Za Zhi. 2020 25;23:I-IV. 
14. Li Y, Huang X, Yu IT, Wong TW, Qian H. Role of air distribution in SARS transmission during the largest nosocomial outbreak in Hong Kong. Indoor Air 2005; 15:83-95.

15. Gao J, Tian Z, Yang X. Breakthrough: Chloroquine phosphate has shown apparent efficacy in treatment of COVID-19 associated pneumonia in clinical studies. Biosci Trends 2020;14:72-73.
16. Mehta P, McAuley DF, Brown M, Sanchez E, Tattersall RS, Manson JJ, et al. COVID-19: consider cytokine storm syndromes and immunosuppression. The Lancet Published Online, 2020

17. Smith T, Prosser T. COVID-19 Drug Therapy - Potential Options. Clinical Drug Information | Clinical Solutions, Elsevier 2020. 